\title{
COEXISTENCE OF PANCREATIC ADENOCARCinoma AND A PSEUDOCYST IN CAT
}

\author{
Magdalena Kulus ${ }^{1}$, Małgorzata Józkowiak², Dorota Bukowska' ${ }^{1}$, Jakub Kulus ${ }^{1}$, Paweł Antosik ${ }^{1}$
}

\begin{abstract}
Exocrine pancreatic tumors in cats and dogs are very uncommon, with exocrine pancreatic adenocarcinoma described as a particularly rare, malignant tumor in a small animals. It is usually derived from pancreatic ducts, as well as glandular tissue. Very often the disease has a subclinical course and is diagnosed only during post - mortem examination. Adenocarcinoma metastasize to both the surrounding and distant organs. The etiology of the cancer progress in the pancreas remains unknown.

Pancreatic pseudocyst (pseudocystis pancreatis) is a very rare disease in domestic animals. Only a few cases of pancreatic pseudocyst in dogs and cats are described in the available literature. On the other hand, in humans it is a common complication of pancreatitis. The pancreatic pseudocyst can be a result of pancreatitis, as well as be a secondary condition to acute pancreatitis, trauma or chronic inflammation. It is a capsule made of fibrous or granulation tissue, containing sterile pancreatic juice. The pathogenesis of pancreatic pseudocyst is still unknown. Clinical signs are not specific and may resemble symptoms of pancreatitis. The ultrasound examination shows a cyst in the pancreas.

This paper describes the case of pancreatic adenocarcinoma in a cat that occurred simultaneously with the pancreatic pseudocyst. Currently, literature indicates the necessity to differentiate the above cancer from cystic lesion. Due to the simultaneous occurrence of both pathologies, extremely rare diagnosis and spectacular picture of changes, it was decided to present this case.
\end{abstract}

Running title: Pancreatic adenocarcinoma with the pseudocyst in cat

Keywords: pancreatic adenocarcinoma in cat, pancreatic pseudocyst in cat, rare pancreatic diseases 


\section{Introduction}

Exocrine pancreatic tumors in cats and dogs are very uncommon $[1,2]$. These cancers are most often malignant epithelial neoplasia (adenocarcinoma) and occur in older patients [3]. In dogs, individuals of some breeds (spaniel, boxer, Airedale terrier, Labrador retriever) are affected more frequently than others. The disease is also slightly more frequent in bitches than males [4]. Exocrine pancreatic adenocarcinoma is described as a rare, malignant tumor in small animals. Is usually derived from pancreatic ducts, as well as the glandular tissue. Very often the disease has a subclinical course and is diagnosed only during post - mortem examination. Organ displacement can occur, as well as cancer necrosis due to destruction of blood vessels. Cancer necrosis may lead to local inflammation, which clinically reveals pancreatitis. Adenocarcinoma may metastasize to both the surrounding and distant organs. The etiology of the cancer progress in pancreas remains unknown [5].

Clinical signs of pancreatic cancer can be very different and not specific. In cats, the most frequently observed were: anorexia, vomiting and abdominal pain, but also lack of appetite, apathy, jaundice, constipation and diarrhea [6-8]. Less frequent symptoms are polyuria, fever, dehydration, abdominal distension and pale mucous membranes $[5,8]$. Several dogs were described with multifocal subcutaneous swelling and necrotic inflammation of adipose tissue coexisting with pancreatic carcinoma [9]. Pancreatic adenocarcinoma can be associated with a dermatologic paraneoplastic syndrome. It occurs as symmetrically located alopecia of the ventrum, face and limbs, as a non - pruritic lesions (unless complicated by secondary infections) [3]. In three cats with pancreatic adenocarcinoma, paraneoplastic alopecia was described [10]. The case of cat in which a strong pruritus was treated with progressive alopecia in the abdomen area was also described. In addition, Malassezia infection has also occurred. The progressive disease led to a deterioration of the patient's condition and lead to euthanasia of the patient. The dissection showed exocrine pancreatic adenocarcinoma with liver metastasis [11]. Changes in serum parameters under investigation may occur but are not specific. Most frequently, bilirubin levels and liver enzymes increase. Lipase and amylase changes in serum are not observed most frequently [5].

Palpation of the abdominal cavity may indicate the accumulation of fluid and sometimes also allows to feel the enlarged structure [4]. Radiological examination may reveal the presence of tumor and dislocation of organs, but it is not a basic diagnostic tool. Ultrasound examination is the most reliable in this case, where the presence of tumor on the pancreas is detected. However, the diagnosis is usually based on diagnostic laparotomy or post - mortem examination. Thin - needle aspiration biopsy and peritoneal fluid aspiration are not always successful [5]. Final diagnosis shall be based on histopathological examination. Cancer cells can form nests of different sizes, bubbles, beads or fields of non-differentiated cells of various sizes. The nuclei of neoplastic cells are small, hyperchromatic and cytoplasm rich, with a pattern typical for pancreatic alveolar cells. Cancers of exocrine pancreas can originate from both types of epithelial cells that build up the organ. More often adenocarcinomas are derived from epithelium of intralobular duct, followed by those originating from vesicular secretion cells [2].

Patients who have a diagnosed adenocarcinoma usually exhibit advanced metastases to other organs $[3,6]$. In cats, in $81 \%$ of cases, metastases are found at the time of diagnosis [2]. The most common locations of metastases are the liver, abdominal and chest lymph nodes, as well as the intestine or lungs and other organs [7]. In rare cases of lack of metastases, surgical pancreatic tumors can be removed with the remaining margin, but the chances of complete healing are negligible [4]. However, there are cases of a long survival after surgical removal of part of the pancreas with cancer and the spleen with visible metastases [1]. The procedure of complete surgical pancreatic removal is very invasive, difficult to perform, with postoperative complications carrying significant indispositions. Prognosis for pancreatic adenocarcinoma in dogs and cats is poor [5].

Pancreatic pseudocyst (pseudocystis pancreatis) is a very rare disease in domestic animals [12]. Only a few cases of pancreatic pseudocyst in dogs and cats are described in the available literature $[13,14]$. On the other hand, in humans it is a common complication of pancreatitis [5]. The pancreatic pseudocyst can be a result of pancreatitis, as well as a secondary condition to acute pancreatitis, trauma or chronic inflammation [12]. It is a capsule made of fibrous or granulation tissue, containing sterile pancreatic juice. The real pancreatic cyst differs from the pseudocyst in wall structure. In a real cyst, the wall is lined with a single layer of cylindrical or cubic epithelium. The pseudocysts are surrounded only by a fibrous bag without epithelial lining [15]. The most common pseudocyst size is $2-7 \mathrm{~cm}$ [13]. The pathogenesis of pancreatic pseudocyst is still unknown. Clinical signs are not specific and may resemble symptoms of pancreatitis [16]. Vomiting is the most common symptom. The patients may also exhibit weight loss and anorexia. Pseudocysts can cause obstruction of the bile duct and, consequently, jaundice [17]. Sometimes it is possible to feel the formation in the abdominal cavity during palpation examination. The ultrasound examination shows a cyst in the pancreas [5]. Ultrasonograms shows anechoic to slightly echoic cyst-like structures in the pancreatic region. They can form single and multiple structures. Within the collected fluid, hyperechoic structures that are for- 
med by sediment and debris can be seen. If a magnifying pseudocyst obstructs the bile duct, a magnification of the gallbladder can be observed [16]. A complete evaluation of the pancreas may be difficult because it is a small organ with indistinct ultrasonographic margins and similar echogenicity to the surrounding fat [18]. Cysts in the left pancreatic lobe were the most common [13]. The ultrasound - guided percutaneous aspiration of cyst fluid can be safely performed for both diagnostic and therapeutic procedures [16]. Lipase and amylase are found in the fluid. Treatment may be conservative or surgical. Surgical treatment should be performed in the presence of large clinical symptoms and when the cyst does not decrease for a long time [5]. Mortality caused by the presence of pancreatic pseudocyst is smaller than that of abscesses or necrotic masses in pancreas [16].

This paper describes the case of pancreatic adenocarcinoma in a cat that occurred simultaneously with the pancreatic pseudocyst. Currently, literature indicates the necessity to differentiate the above cancer from cystic lesion. Due to the simultaneous occurrence of both pathologies, extremely rare diagnoses and spectacular picture of changes, it was decided to present this case.

\section{Materials and methods}

A 15-year-old, female, spayed, European breed cat, weighing $4,8 \mathrm{~kg}$, was presented to veterinary hospital to evaluation with history of weight loss, apa- thy and diarrhea with blood over the previous 2 days. Full blood count was performed by using Mythic 18 Orphee, biochemistry serum tests - Pointe 180. On physical examination, a significant degree of dehydration has been found, the coat was dull and dry. The rectal temperature, respiratory rate and pulse rate were all within normal ranges. Palpation revealed the presence of a round formation in the area of the xiphoid process of sternum. An ultrasound was performed, confirming the presence of a cystic lesion in the region of the lower abdomen. Ultrasound examination (MyLabOne, 5-10 MHz) of the abdomen identified a regularly shaped, hypoechogenic cystic lesion filled with fluid. This cystic lesion, $5 \mathrm{~cm}$ in size (Fig. 1), contained hyperechogenic suspended material. The pancreas exhibited general magnification, with rounded edges. The rest of organs in the ultrasound examination did not show any abnormalities. The hematological and serum biochemistry findings were within normal ranges (Tab. 1,2). The X-ray examination of the abdomen and chest was performed to exclude the presence of metastases. Based on the clinical findings the animal was given essential medication (broad spectrum antibiotics, NSAID) and intravenous fluid therapy (Solution Ringeri). A diagnostic laparotomy was recommended.

During the surgery a cyst was observed, which showed a strong connection with the duodenum segment (adhesion) (Fig. 2). It had a thick, fibrous bag, with its size and advancement of the pathologi-

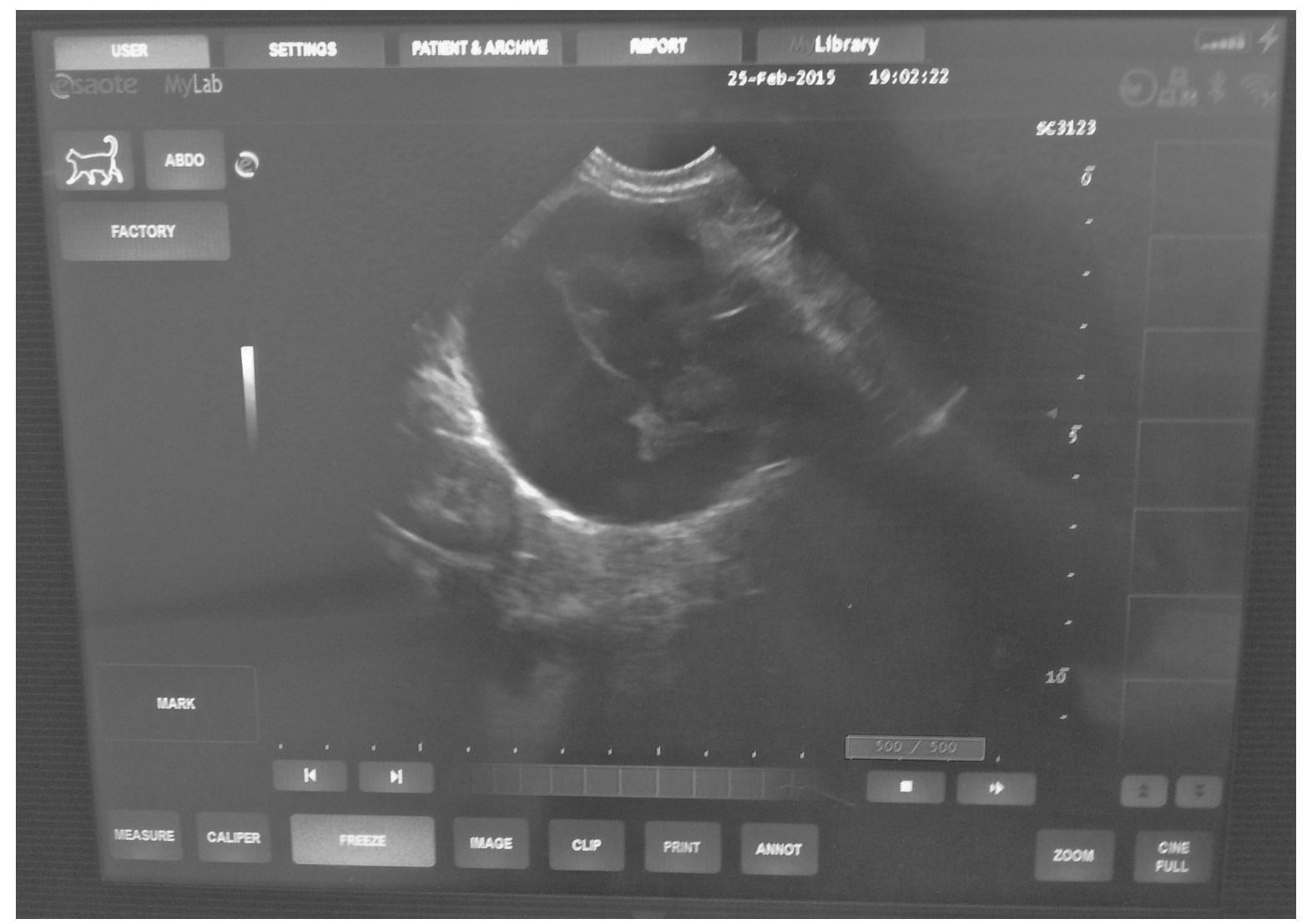

FIGURE 1 The ultrasound examination showing cystic lesion 
TABLE 1 The hematological findings

\begin{tabular}{c|c|c|c}
\hline PARAMETER & RESULT & UNIT & NORM \\
\hline WBC & 7,7 & $10^{3} / \mu \mathrm{l}$ & $5,5-19,0$ \\
\hline LYM & 3,3 & $10^{3} / \mu \mathrm{l}$ & $1,0-5,0$ \\
\hline MON & 0,2 & $10^{3} / \mu \mathrm{l}$ & $0,1-1,0$ \\
\hline GRA & 4,2 & $10^{3} / \mu \mathrm{l}$ & $2,0-8,0$ \\
\hline LYM \% & 42,9 & $\%$ & $20,0-55,0$ \\
\hline MON \% & 3,1 & $\%$ & $1,0-4,0$ \\
\hline GRA \% & 54,0 & $\%$ & $35,0-75,0$ \\
\hline RBC & $\mathbf{1 0 , 1 2}$ & $10^{6} / \mu \mathrm{l}$ & $6,5-10,0$ \\
\hline HGB & $\mathbf{1 7 , 6}$ & $\mathrm{g} / \mathrm{dl}$ & $8,0-15,0$ \\
\hline HCT & $\mathbf{4 7 , 3}$ & $\mathbf{\%}$ & $24,0-45,0$ \\
\hline MCV & 46,7 & $\mu \mathrm{m}^{3}$ & $39,0-55,0$ \\
\hline MCH & $\mathbf{1 7 , 4}$ & $\mathrm{pg}$ & $13,0-17,0$ \\
\hline MCHC & $\mathbf{3 7 , 2}$ & $\mathrm{g} / \mathrm{dl}$ & $30,0-36,0$ \\
\hline RDW & $\mathbf{1 6 , 4}$ & $\%$ & $10,0-16,0$ \\
\hline PLT & $\mathbf{4 8 1}$ & $10^{3} / \mu \mathrm{l}$ & $100-400$ \\
\hline MPV & 10,1 & $\mu \mathrm{m}^{3}$ & $7,0-11,0$ \\
\hline
\end{tabular}

TABLE 2 The serum biochemistry findings

\begin{tabular}{c|c|c|c}
\hline PARAMETER & RESULT & UNIT & NORM \\
\hline ALT (GPT) & 26,4 & $\mathrm{IU} / \mathrm{L}$ & $20-107$ \\
\hline AST (GOT) & 34,1 & $\mathrm{IU} / \mathrm{L}$ & $6-44$ \\
\hline UREA & 31,5 & $\mathrm{mg} / \mathrm{dL}$ & $25-70$ \\
\hline CREATININE & 1,7 & $\mathrm{mg} / \mathrm{dL}$ & $1-1,8$ \\
\hline AP & 17,6 & $\mathrm{IU} / \mathrm{L}$ & $23-107$ \\
\hline
\end{tabular}

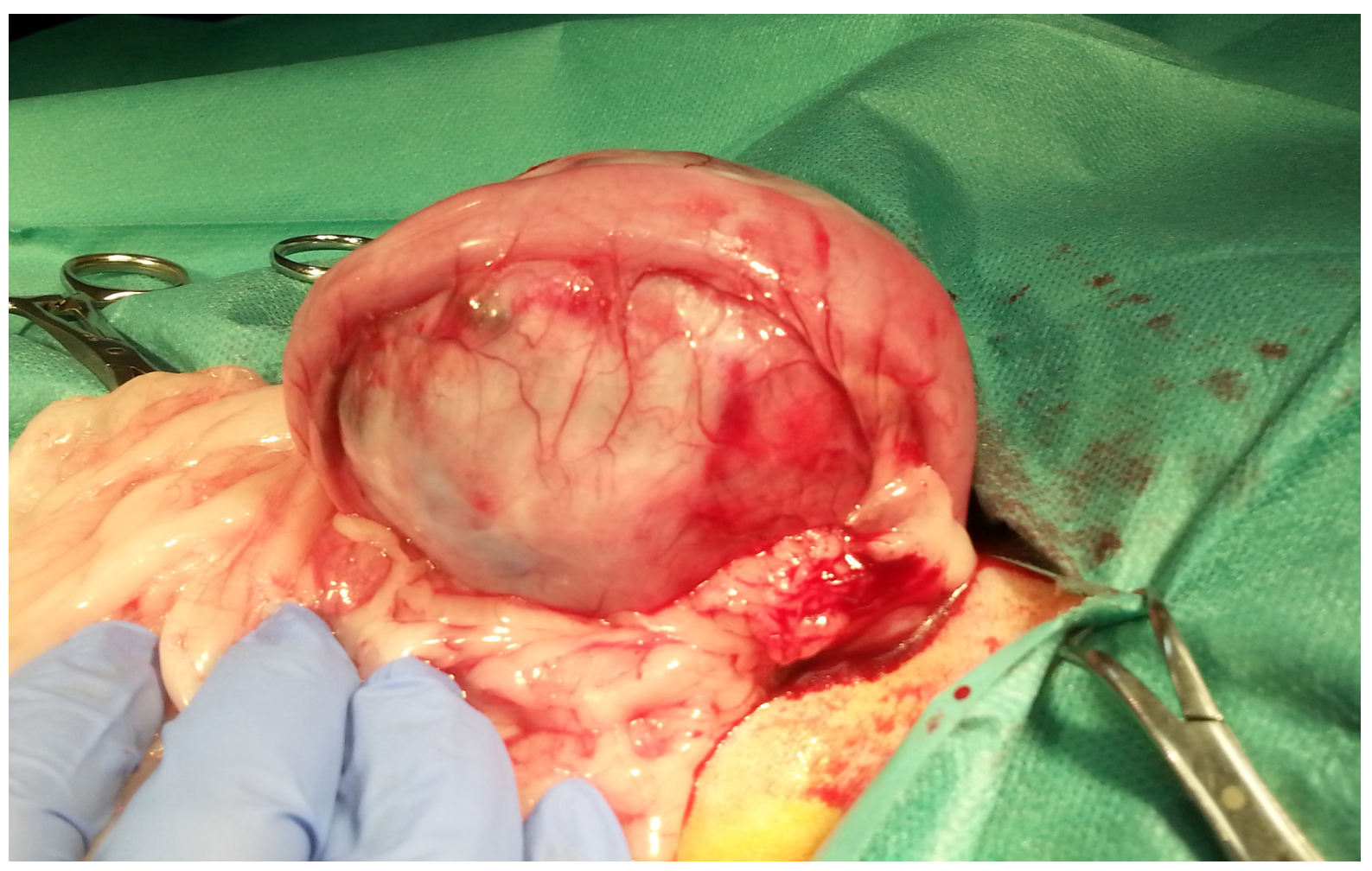

FIGURE 2 Adhesion of cystic lesion to duodenum 
cal process significantly influencing the functioning of abdominal organs. Considering the nature of the changes, their advancement, the age of the patient (15 years) as well as the difficulty of performing the procedure and the high postoperative mortality associated with it, it was decided to perform euthanasia. The cyst emerged from the pancreatic parenchyma (Fig. 3), which also showed changes (swelling, nodule and thickened surface, enlargement, hardening). Inside the cyst there was a liquid content of a bloody and clear character with fiber aggregates (Fig. 4). Samples were taken for histopathological examination, fixed in $10 \%$ buffered formalin, embedded in paraffin wax, sectioned at $4 \mu \mathrm{m}$ and then stained with hematoxylin and eosin (H\&E).

\section{Ethical approval}

The research related to animal use has been complied with all the relevant national regulations and instructional policies for the care and use of animals. Bioethical Committee approval not required.

\section{Results}

The lesion was described as malignant tumor originating from pancreatic acinar cells. The mass was surrounded by thick fibrous capsule. The tumor consisted of variable lobules and trabeculae with acini formation. These acini consisted of polygonal cells which often contained zymogene granules. Mitoses averaged 2 per 10 HPFs. Within the remaining pancreatic tissue, the pancreatic lobules were surrounded by reactive fibrous tissue and exhibited variably atrophy. The behavior of the cancer was malignant, of locally invasive growth and metastatic. The mass associated with pancreas represented pancreatic acinar adenocarcinoma, confirming the presence of a pancreatic pseudocyst.

\section{Discussion}

Pancreatic exocrine carcinoma is infrequently diagnosed in animals. It is a relatively rare tumor in cats, with an incidence of less than 0,5\% [3]. Symptoms may not be specific, and the diagnosis may be

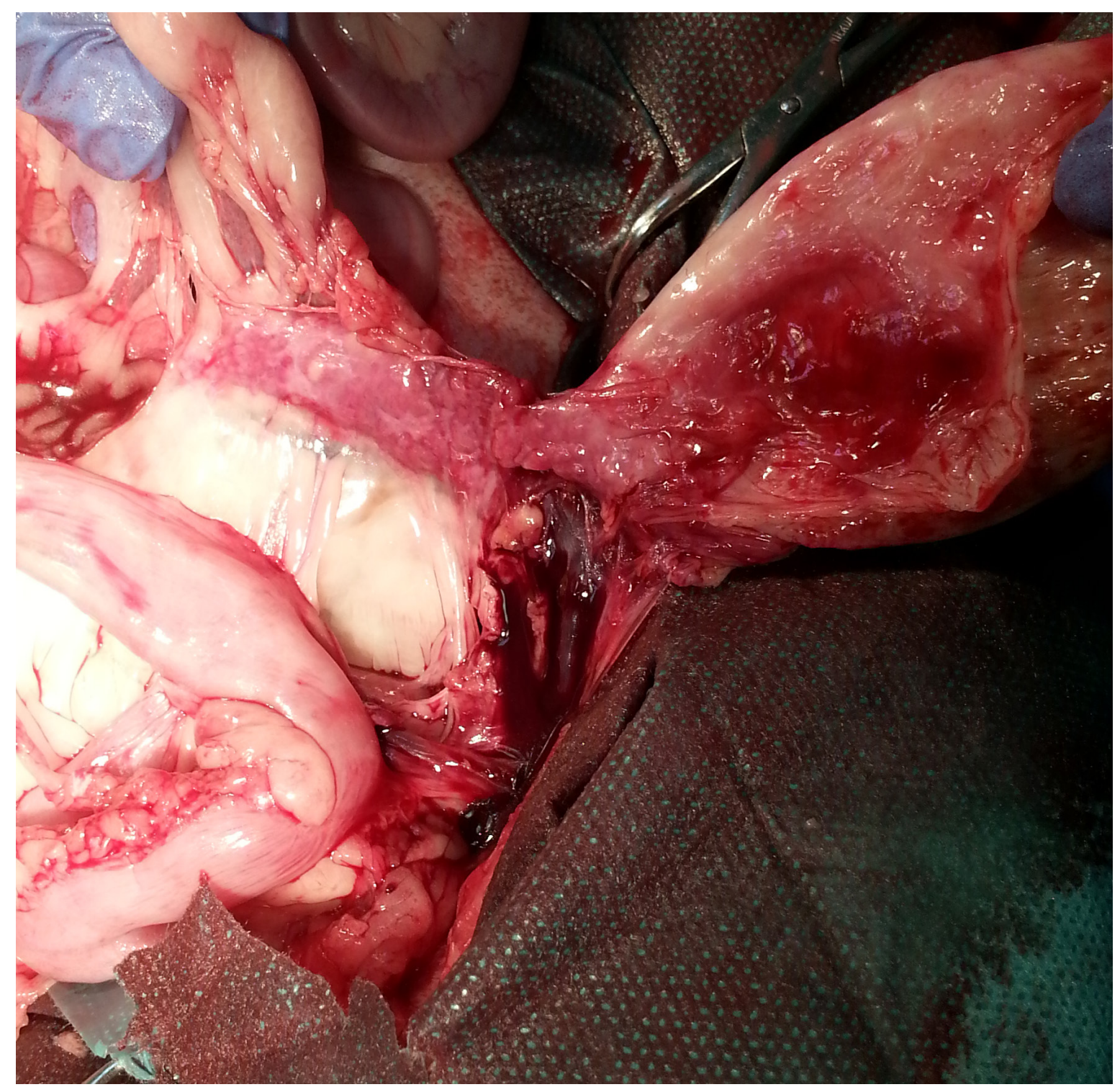

FIGURE 3 The cyst emerged from the pancreas parenchyma 


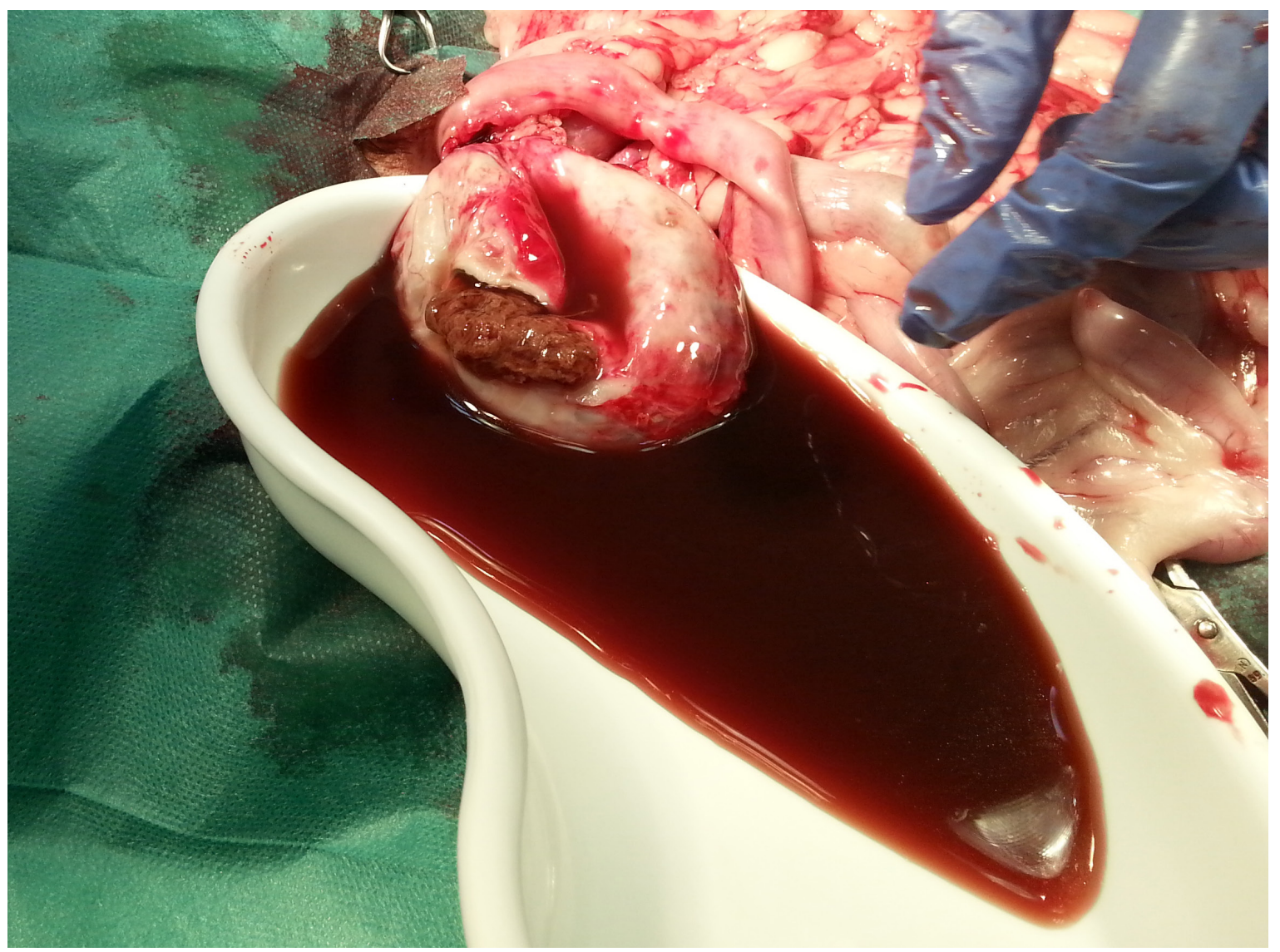

FIGURE 4 Liquid content of a bloody and clear character with fibrous aggregates

made so late that metastases will already be present. Often, surgery does not provide complete healing. In the case series review study on 8 sick cats, all of them died or were euthanized within 7 days of the diagnosis [7]. The average survival time is very short due to the rapid progress of the disease and early metastases. There are still too few reported cases of pancreatic cancer in cats and responses to treatment.

Pancreatic cysts, which are a common complication of pancreatitis in humans, are a rare pathology in animals. Precise data on the prevalence of the disease in pets is not known, but several cases have been reported so far in dogs $[13,17,19,20]$. In cats, however, a pancreatic pseudocyst was described in 1996 for the first time [14], with a pancreatic true cyst described in 2005 [12]. Later, in 2010, the case of recurrent true cysts of pancreas of unknown etiology was mentioned [21]. Prognoses for patients with small pancreatic cysts that do not cause symptoms are successful or cautious. Causal treatment (when pancreatitis is diagnosed) should be implemented and the lesion should be observed. Periodic ultrasound examination provides an opportunity to observe the dynamics of changes. In the case of a large cyst and necessary surgical procedure, prognosis may be poor [15].

In the differential diagnosis of adenocarcinoma, it is recommended to differentiate it from a pancreatic pseudocyst [2]. In this case, both changes occurred simultaneously and most probably the pseudocyst was secondary to the tumor. A pseudocyst is a benign lesion whose treatment could be successful. However, the presence of malignant cancer in this case was crucial in condemning the patient to treatment failure and causing death. It is assumed that the pathogenesis of the changes described in this paper starts with the growth of adenocarcinoma, which caused local neoplastic necrosis. Then, a local inflammatory reaction took place, which led to degenerative changes and, in consequence formation of a cyst, which exhibited neoplastic infiltration. The presence of cells of this cancer in the pseudocyst wall indicated its strong ability to infiltrate tissues.

This case is an evidence of the possibility of coexistence of these conditions. The paper additionally presents the subject of two rarely diagnosed diseases of small animals, the actual occurrence of which may be more frequent.

\section{Corresponding author}

Paweł Antosik, Veterinary Centre, Nicolaus Copernicus University in Toruń, 7 Gagarina St., Toruń, Poland, tel. +48 56 6112231, +48 56 6113093, e-mail: pantosik@umk.pl.

\section{Conflict of interest statement}

The authors declare they have no conflict of interest.

\section{References}

1. Rosatelli P, Menicagli F, Citro G, Baldi a., Spugnini EP. Long-Term Survival in a Cat with Pancreatic Carcinoma and Splenic Involvement 
after Surgical Excision. Case Reports Vet Med. 2011;2011:1-3; DOI: $10.1155 / 2011 / 653859$.

2. Sapierzyński R. Nowotwory układu pokarmowego u psów i kotów. Częśc III. Nowotwory ślinianek, wątroby i części zewnątrzwydzielniczej trzustki. Życie Weter. 2006;81(6):388-95.

3. Linderman MJ, Brodsky EM, de Lorimier L-P, Clifford CA, Post GS. Feline exocrinepancreaticcarcinoma: aretrospective study of 34 cases. VetComp Oncol. 2013;11(3):208-18; DOI: 10.1111/j.1476-5829.2012.00320.x

4. Sapierzyński R. Onkologia praktyczna psów i kotów. Wrocław: Elsevier Urban \& Partner. 2010.

5. Steiner JM. Choroby przewodu pokarmowego psów i kotów. Galaktyka. 2009:283-304

6. Andrews LK. Tumors of the exocrine pancreas. In: Diseases of the cat Saunders. 1987:505-7.

7. Seaman RL. Exocrine Pancreatic Neoplasia in the Cat: A Case Series. J Am Anim Hosp Assoc. 2004;40(3):238-45; DOI: 10.5326/0400238.

8. Haines VL, Brown PR, Hruban RH, Huso DL. Adenocarcinoma of the Hepatopancreatic Ampulla in a Domestic Cat. Vet Pathol. 1996;33(4):439 41; DOI: $10.1177 / 030098589603300413$.

9. Brown PJ, Mason K V., Merrett DJ, Mirchandani S, Miller RI. Multifocal necrotising steatites associated with pancreatic carcinoma in three dogs. J Small Anim Pract. 1994;35(3):129-32; DOI: 10.1111/j.17485827.1994.tb03913.x

10. Brooks DG, Campbell KL, Dennis JS, Dunstan RW. Pancreatic paraneoplastic alopecia in three cats. J Am Anim Hosp Assoc. 1994;30:557-63.

11. Godfrey DR. A case of feline paraneoplastic alopecia with secondary Malassezia-associated dermatitis. J Small Anim Pract. 1998;39(8):394-6.

12. Coleman MG, Robson MC, Harvey C. Pancreatic cyst in a cat. N Z Vet J. 2005;53(2):157-9; DOI: 10.1080/00480169.2005.36495.

13. VanEnkevort BA, O’Brien RT, Young KM. Pancreatic pseudocysts in 4 dogs and 2 cats: ultrasonographic and clinicopathologic findings. J Vet Intern Med. 1999;13(4):309-13; DOI: 10.1111/j.1939-1676.1999. tb02186.x.

14. Hines BL, Salisbury SK, Jakovljevic S, DeNicola DB. Pancreatic pseudocyst associated with chronic-active necrotizing pancreatitis in a cat. J Am Anim Hosp Assoc. 1996;32(2):147-52; DOI: 10.5326/15473317-32-2-147.

15. Fojut-Pałka B. Torbiele trzustki u psów i kotów. Mag Weter. 2013; 22(196):844-7.

16. Coleman M, Robson M. Pancreatic Masses Following Pancreatitis: Pancreatic Pseudocysts, Necrosis, and Abscesses. Compend Contin Educt Pr Vet. 2005;27(2):147-54

17. Marchevsky AM, Yovich JC, Wyatt KM. Pancreatic pseudocyst causing extrahepatic biliary obstruction in a dog. Aust Vet J. 2000;78(2):99-101; DOI: 10.1111/j.1751-0813.2000.tb10534.x.

18. Panagiotis M. Ultrasonography of the Gastrointestinal Tract and Pancreas of the Dog and Cat. Iran J Vet Surg. 2008;Supplement:57-62.

19. Bellenger CR, Ilkiw JE, Malik R. Cystogastrostomy in the treatment of pancreatic pseudocyst/abscess in two dogs. Vet Rec. 1989;125(8):181-4

20. Smith S, Biller D. Resolution of a pancreatic pseudocyst in a dog following percutaneous ultrasonographic-guided drainage. J Am Anim Hosp Assoc. 1998;34(6):515-22; DOI: 10.5326/15473317-34-6-515.

21. Branter EM, Viviano KR. Multiple recurrent pancreatic cysts with associated pancreatic inflammation and atrophy in a cat. J Feline Med Surg. 2010;12(10):822-7; DOI: 10.1016/j.jfms.2010.06.005. 